\title{
Reliability-Based Design of Structural Members for Nuclear Power Plants
}

\author{
U. SCHNEIDER \\ University of Kassel \\ Mönchebergstr. 7, D-3500 Kassel, Germany \\ D. HOSSER \\ König \& Heunisch \\ Oskar-Sommer-Str. 15-17, D-6000 Frankfurt 70, Germany
}

\section{ABSTRACT}

The reliability of load bearing structural members in NPP has been proved by 1st order reliability theory. Studies on the temperature development in safety related compartments and the failure probability of adjacent concrete members were performed. Special effects $e . g$. due to forced ventilation and fire extinguishing systems are accounted for in the calculations with a post-flashover heat balance model. Simplified failure models describing the load bearing capacity of concrete members were applied to check the reliability of different types of building members. The results indicate that the member temperatures and the Iife loads are the most important parameters. Therefore the practical design may be performed by using partial factors for the temperatures and reduction factors for the life loads. It turned out that as a rule 90 minutes fire duration acc. to DIN 4102 is a sufficient value for NPP fire compartments.

\section{INTRODUCTION}

Within a comprehensive research program SR $144 / 1 /$, sponsored by the Federal Minister of the Interior, the requirements for structural fire safety in NPP in Germany were checked with respect to the effect of natural and standardized fires. The report presents one part of the whole investigation program whereby the following topios will be discussed:

- modelling and estimating of fire effects in safety related compartments of a NPP with a pressure water reactor (PWR),

- simplif'ied structural models for the assessment of concrete building elements for NPP,

- probabilistic assessment of structural members under natural and standard fires.

\section{HEAT MODELS FOR STRUCTURAL FIRE SAFETY}

\subsection{Fundamentals}

The prediction of time-temperature curves for compartments in NPP is very complicated because there are many influencing parameters. Up to now, a complete physical model for compartment fires is not at hand. The theoretical basis of such calculation methods is given by the fundamental equations of heat and mass transfer which are applied in the whole compartment or in certain parts of it. The fire development is highly influenced by the following parameters: 
- type and amount of combustible material,

- distribution, density and temperature of the fire load,

- oxygen supply to the burning surface of the material,

- ventilation of the compartment,

- thermal inertia of the building elements,

- influence of extinguishing systems.

For the sake of simplicity and with respect to the special question of fire design of structural members this report refers to a fire model for fully developed compartment fires /2/. The phase of ignition and fire spread in the model is accounted for by a simplified simulation procedure with variable spreading rates. The fire exposure of the structural members is related to the average compartment temperatures. The energy balance in the model is described by six energy terms comprising:

- combustion energy due to a ventilation controlled or fuelbed controlled fire,

- convective energy losses due to a natural or forced ventilation of the compartment,

- radiative energy losses through openings,

- energy losses due to the absorption of the building elements,

- intrinsic energy of the compartment gases and heat sinks,

- absorption energy losses due to the activation of extinguishing systems.

The developed heat release model was calibrated by the data of fire tests derived from expeximents with two types of fire loads. This limitation meets the current practice as the combustible materials in German NPP are more or less limited to oil in closed tanks and cable trays of different types and geometries.

\subsection{Temperature-Time Curves}

During the study 10 safety related areas in a NPP of a German PWR were investigated. The probable type of fire development was determined by a comprehensive sensitivity study. Main results of the heat balance calculations are published in $/ 2 /$. In the following are discussed the results of calculations concerning a cable fire in a cable room of $340 \mathrm{~m}^{2}$ floor area and an oil fire in an oil tank storage depot of $58 \mathrm{~m}^{2}$, with an oil cup of $18 \mathrm{~m}^{2}$.

For the cable room it was assumed that the initial fire area is $0.3 \mathrm{~m}^{2}$. The average spreading rate on the cable trays was fixed at a rate of $1.0 \mathrm{~cm} / \mathrm{s}$ which is an estimate on the safe side according to existing experiences. The whole cable tray area comprises $56 \mathrm{~m}^{2}$. Fig. 1 shows the temperature-time curves for this room. Main parameter is the ventilation as the total fire load is fixed with $9000 \mathrm{~kg}$ FVC. The results indicate significant differences vith respect to the different types of ventilation. The natural ventilation ( 2 doors open) leads to unfavourable conditions. On the other hand the time delay for the activation of the water spray system is comparatively large when the forced ventilation system works.

The simulations of oil tank fires led to similar results. A natural ventilation due to door openings leads to the worst cases (Fig. 2). In the calculations it was assumed that the leckage oil burns in an oil cup whereby the burning rates were controlled by the ventilation. The whole oil tank with $25.000 \mathrm{~kg}$ oil acted as a heat sink in the program and the temperature increase of the oil was calculated by assuming a mixed temperature for the fluid. The boiling point of the oil was not taken into account, but Fig. 2 indicates that boiling might occur after 40 to 50 minutes if no active fire protection measures are undertaken. The water spray system is early activated in this case and the suppression of 
the fire is performed within 5 minutes if an automatic activation system is installed.

\section{DESIGN MODELS FOR REINFORCED CONCRETE MEMBERS}

\subsection{General Assumptions}

In the following, the reliability of load bearing reinforced concrete members e.g. a reinforced concrete ceiling, beam, wall and column (Fig. 3) under fire attack is investigated. Such elements are common for the switch-gear building, respectively. The following conservative assumptions are made:

- The simply supported members are designed for nominal loads (permanent and variable loads) according to the German standard DIN $1045 / 3 /$.

- With respect to the fire safety a design according to the standard DIN 4102 $11 /$ is assumed.

- The temperature exposure is choosen according to i) the standard time-temperature curve and $i i)$ a natural fire which might occur in a typical cable room of a switch-gear building under sufficient natural ventilation (Fig. 1).

In detail the calculations comprise the following tasks:

- Estimating the temperatures within the builaing elements with respect to the compartment temperatures and determining the related material properties.

- Calculating the load-bearing capacity of the building elements under external loads and temperature stresses.

- Performing a probabilistic reliability analysis with regard to the statistical values of the essential parameters.

\subsection{Temperature Increase of the Structural Members}

The temperature profiles of the members are determined by heat-balance calculations for each time step. From these profiles the mean value of the temperatures of the reinforcing steel bars in the tension zone and the mean value of the concrete element temperatures in the compression zone are computed. In the elements according to Fig. 3 mainly the mean temperature of the reinforcement in the tension zone is of interest. This does not hold for the temperatures in the column. Fig. 4 shows the average concrete $\left(\mathrm{T}_{\mathrm{b}}(t)\right)$ and reinforcement $\left(\mathrm{T}_{\mathrm{S}}(t)\right)$ temperatures of the four investigated members under standard (dott.lines) and natural (full Iines) fire conditions. The temperature-dependent material properties were determined by the help of the design curves given in literature $/ 4 /$.

\subsection{Design Equations}

The safety margin of reinforced concrete members like ceilings and beams may be determined as follows:

$\mathrm{Z}=\mathrm{M}_{\mathrm{R}}(t)-\mathrm{M}_{\mathrm{S}} \geq 0$

$\mathrm{M}_{\mathrm{R}}(t)=$ bending moment capacity

$\mathrm{M}_{\mathrm{S}}^{\mathrm{R}}$ = actual bending moment in the critical cross section

The bending moment capacity $M_{R}$ may be approximated by /5/:

$M_{R}(t)=A_{S} \cdot B_{S}\left(T_{S}\right) \cdot z$ 


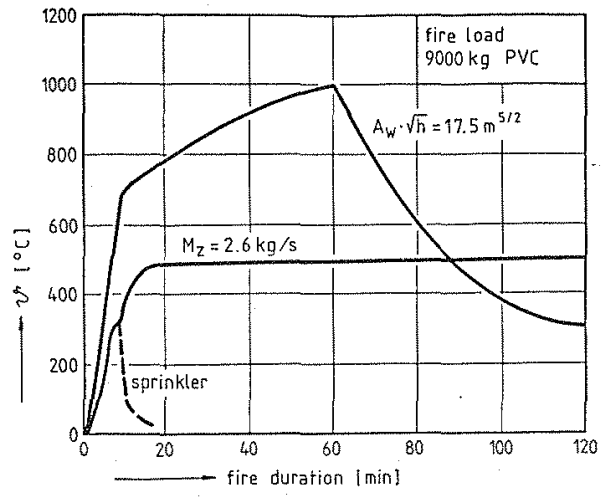

Fig. 1: Temperature-time curves of a cable room

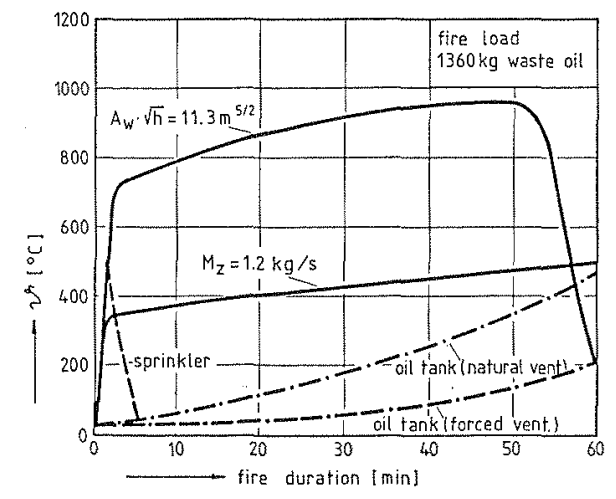

Fig. 2: Temperature-time curves of an oil tank storage deposit

ceiling
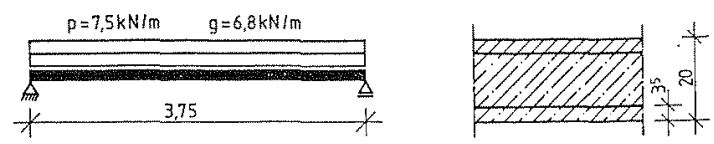

beam
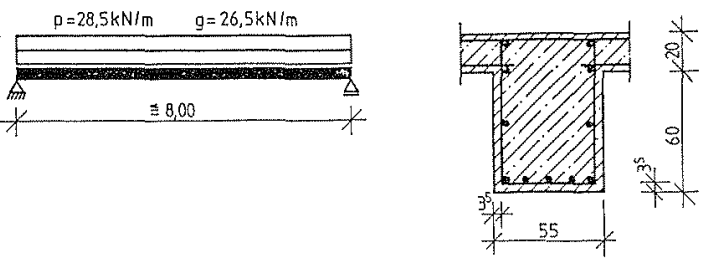

wall

column
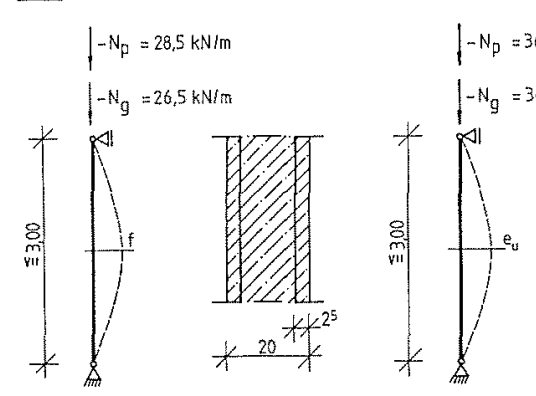

Fig. 3: Assumed building members and load actions for the probabilistic investigations 
with area $A_{S}$ of tension reinforcement, temperature-dependent yield strength $\mathrm{B}_{\mathrm{S}}\left(\mathrm{T}_{\mathrm{S}}\right)$ and internal leverarm $z$. The actual bending moment is:

$M_{S}=(g+p) \cdot 1^{2} / 8$

with the distributed load $\mathrm{g}$ and $\mathrm{p}$ acc. to Fig. 3.

The bending moment capacity of summetrically reinforced walls and colums may be derived as follows:

$M_{R}(t)=\left(1+1.5 \cdot\left(0.7 \frac{h^{\prime}}{d}\right)\right) \cdot\left(0.42 \cdot A_{S} \cdot B_{S}\left(T_{S}\right) \cdot a+0.35 \cdot N \cdot d\right)$

for $N \leqq N_{1}=0.4 \cdot B_{R}\left(T_{b}\right) \cdot b \cdot d$

and

${ }_{M_{R}}(t)=\left(1+1.5 \cdot\left(0.1 \frac{h^{\prime}}{d}\right)\right) \cdot\left(0.42 \cdot A_{S} \cdot B_{S}\left(T_{S}\right) \cdot d+0.35 \cdot N_{1} \cdot d\right)-0.26\left(N-N_{1}\right) \cdot d$

for $\mathrm{N}>\mathbb{N}_{1}$ and $\mathrm{N}=\mathrm{N}_{\mathrm{g}}+\mathrm{N}_{\mathrm{p}}$ according to Fig. 3 .

Usually walls and columns are stressed by normal loads. In addition the columns are subjected to bending moments due to an unintended eccentricity e after $/ 3 /$. Walls are subjected to bending moments due to the one-dimensional fire attack. The action of external loads is determined by

$M_{S}(t)=N \cdot e\left(1+\frac{1}{8} \cdot \frac{N \cdot I^{2}}{E I_{W}(t)}\right)$

$e=e_{u}$ for colums and $e=f=\frac{I^{2}}{8} \cdot \alpha_{\mathrm{T}} \cdot \frac{\Delta \mathrm{T}}{\mathrm{d}}$ for walls

E $I_{W}(t)=$ flexural stiffness $\left(\mathrm{kN} / \mathrm{cm}^{2}\right)$

\section{RELIABILITY ANALYSIS}

\subsection{Introduction to the Method}

The reliability analysis of concrete members is performed for the ultimate limit states defined by the design models in chapter 3 . The basic variables $x_{i}$ of the models are described by distribution functions. With the help of the errox propagation law the mean value $m_{z}$ and standard deviation $\sigma_{z}$ of the safety margin $z$ according to equ.(1) is determined. The quotient

$B=m_{z} / \sigma_{z}$

is called safety index and is used as a measure of reliability. The scattering effects of the basic variables $x_{j}$ with respect to the safety index $B$ can be evaluated by the so-called weighting factors $\alpha_{x_{i}}$ :

$\alpha_{x_{i}}=\frac{\partial z}{\partial x_{i}} \cdot \sigma_{x_{i}} / \sqrt{\sum_{j=1}^{n}\left(\frac{\partial z}{\partial x_{i}} \sigma_{X_{i}}\right)^{2}}$

with the partial derivatives $\partial z / \partial \mathrm{x}_{i}$ and the standard deviations $\sigma_{\mathrm{X}}$. The safety index $B$ and the weighting factors ${ }^{1} \alpha_{X_{j}}$ depend on the time $t$ after fire occurance. 

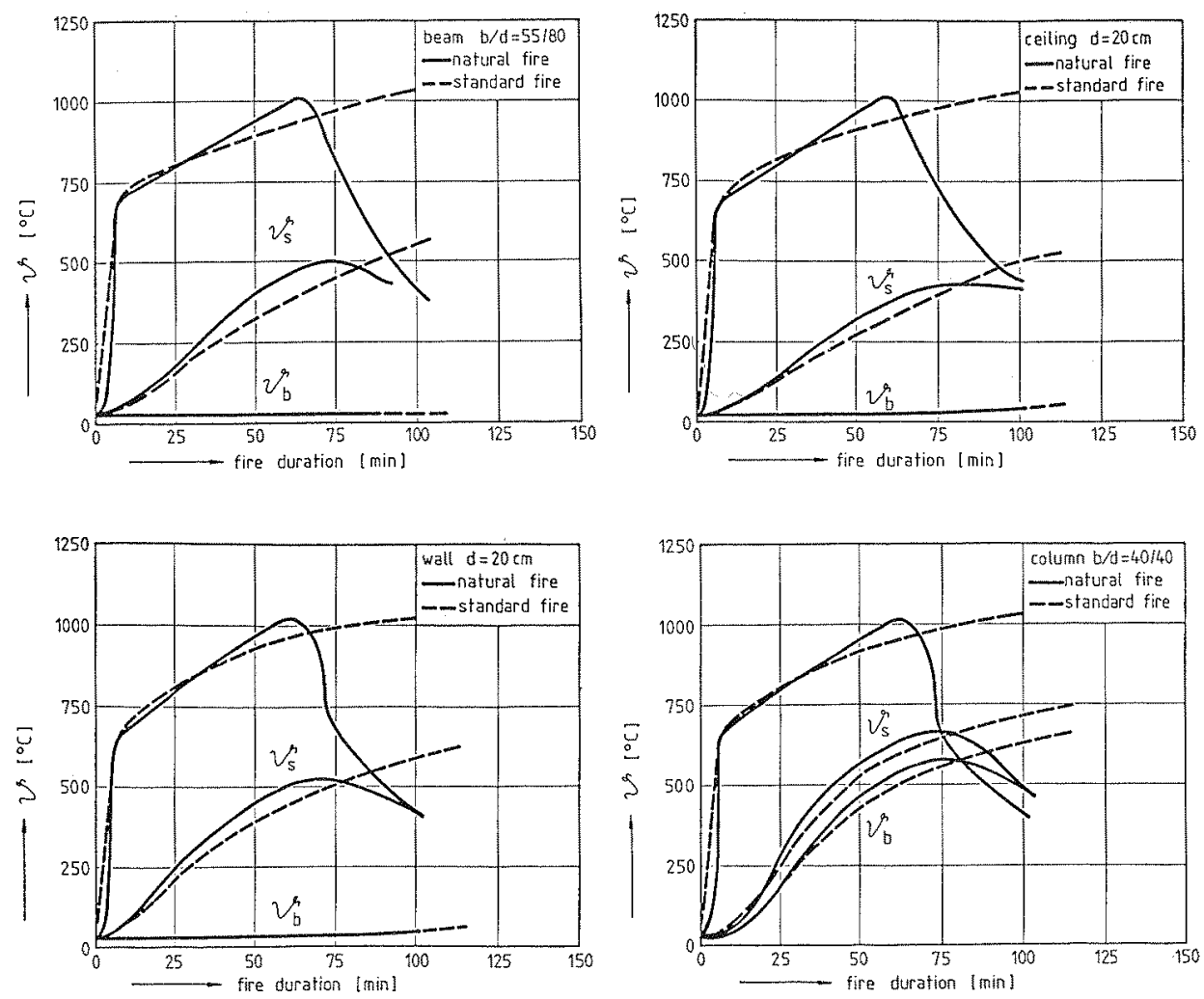

Fig. 4: Compartment and member temperatures of the investigated structural members

\subsection{Random Variations and Uncertainties}

Distribution functions for the most important parameters (basic variables) of the design models in chapt. 3 were chosen according to /5/. On Tab. 1 the nominal values of those parameters are defined as percentiles, in addition the types of distribution functions and the coefficients of variations are given. The numbers are in aggreement with those values which have been determined by performing several comparison calculations in the field of reinforced concrete design. The variation of the standard fire temperature-time curve are specified. according to DIN 4102 , part $2 / 1 /$.

The variations of the temperature-time curve $T(t)$ in natural fires mainly depend on the

- specific rate of combustion $\dot{\mathrm{R}}_{\mathrm{Bn}}$ in $\mathrm{kg} / \mathrm{m}^{2} \mathrm{~h}$ and the burning area,

- ventilation conditions, e.g. Ventilation area $A_{W}$ or ventilation rate $M_{Z}$,

- amount of combustible material, e.g. fire load q, 
Tab. 1: Distribution assumptions for the basic variables of the design models

\begin{tabular}{|c|c|c|c|c|}
\hline Parameter & $\begin{array}{l}\text { nominal. } \\
\text { value }\end{array}$ & $\begin{array}{l}\text { distribution } \\
\text { function }\end{array}$ & $\begin{array}{l}\text { coefficient } \\
\text { of variation }\end{array}$ & comment \\
\hline T, stand. fire & mean & log. normal & 0.10 & DIN 4102 \\
\hline T, nat. fire & mean & log. normal & 0.20 & Fig. 4 \\
\hline reinf. temp. $\mathrm{T}_{\mathrm{s}}$ & mean & log. normal & 0.20 & Fig. 4 \\
\hline concrete temp. $\mathrm{I}_{\mathrm{b}}$ & mean & log. normal & 0.20 & Fig. 4 \\
\hline yield strength $B_{\mathrm{S}}$ & $5 \%$ & log. normal & 0.06 & acc. to $/ 5 /$ \\
\hline concrete strength $B_{R}$ & $5 \%$ & log. normal & 0.15 & acc. to $/ 5 /$ \\
\hline steel mod. $\mathrm{E}_{\mathrm{S}}$ & mean & log. normaI & 0.05 & acc. to $/ 5 /$ \\
\hline concrete mod. ${ }^{{ }} b$ & mean & log. normal & 0.10 & acc. to $/ 5 /$ \\
\hline reinf. cover u & mean & log. normal & 0.25 & acc. to $/ 5 /$ \\
\hline perm. Ioad $\mathrm{g}$, Ng & mean & normal & 0.05 & acc. to $/ 5 /$ \\
\hline live load & $98 \%$ & extremal I & 0.40 & natural fire \\
\hline 1oad $\mathrm{p}, \mathrm{Np}$ & $57 \%$ & one year max. & 0.05 & DIN 4102 \\
\hline
\end{tabular}

in the respective compartment. Sensitivity studies in $/ 5 /$ led to the conclusion that during a fully-developed fire the standard deviation $\sigma_{\mathrm{T}}$ of the gas temperature $T$ is nearly constant and may be evaluated as follows:

$\sigma_{\mathrm{T}(\mathrm{t})}=\sqrt{\left(\frac{\Delta \mathrm{T}}{\Delta \mathrm{R}_{\mathrm{Sp}}} \cdot \sigma_{\dot{R}_{\mathrm{Sp}}}\right)^{2}+\left(\frac{\Delta \mathrm{T}}{\Delta \mathrm{A}}{ }_{\mathrm{W}} \cdot \sigma_{\mathrm{A}}\right)^{2}+\left(\frac{\Delta \mathrm{T}}{\Delta \mathrm{M}_{\mathrm{Z}}} \cdot \sigma_{\mathrm{M}_{\mathrm{Z}}}\right)^{2}}$

The standard deviations of the element temperatures $T_{b}(t)$ and $T_{s}(t)$ are lower than $\sigma_{\mathrm{T}}(t)$. But the coefficients of variation approximately correspond to the coefficient of variation $V_{T}(t)$ of the gas temperature which aepends on the fire duration. A maximum value $V_{T}(t) \approx 0.17$ has been estimated under different assumptions in $/ 5 /$ and $/ 2 /$.

In addition to the variations of the gas temperature one must consider the variations of the fire duration which is a - more or less linear - function of the fire load $q$. Under the assumption that in a NPP the determination of fire loads is individually performed a coefficient of variation $v_{q}=0.1$ may be a sufficiently conservative estimate. As during the phase of a fully-developed fire the element temperatures increase nearly proportionally to the fire duration, the coefficient of variation $v_{q}$ results in an additional variation of the element temperatures $\mathrm{T}_{\mathrm{b}}$. Assuming independence of the random variations of $T$ and $q$ the overall coeficient of variation may be derivea,

$\mathrm{V}_{\mathrm{T}, \mathrm{s}}=\sqrt{\mathrm{V}_{\mathrm{T}(\mathrm{t})^{2}+\mathrm{V}_{\mathrm{q}}{ }^{2}}}$

yielding $\mathrm{V}_{\mathrm{T}_{\mathrm{b}, \mathrm{S}}} \approx 0.2$ (cf $\left.\mathrm{Tab} .1\right)$ as an average value. 

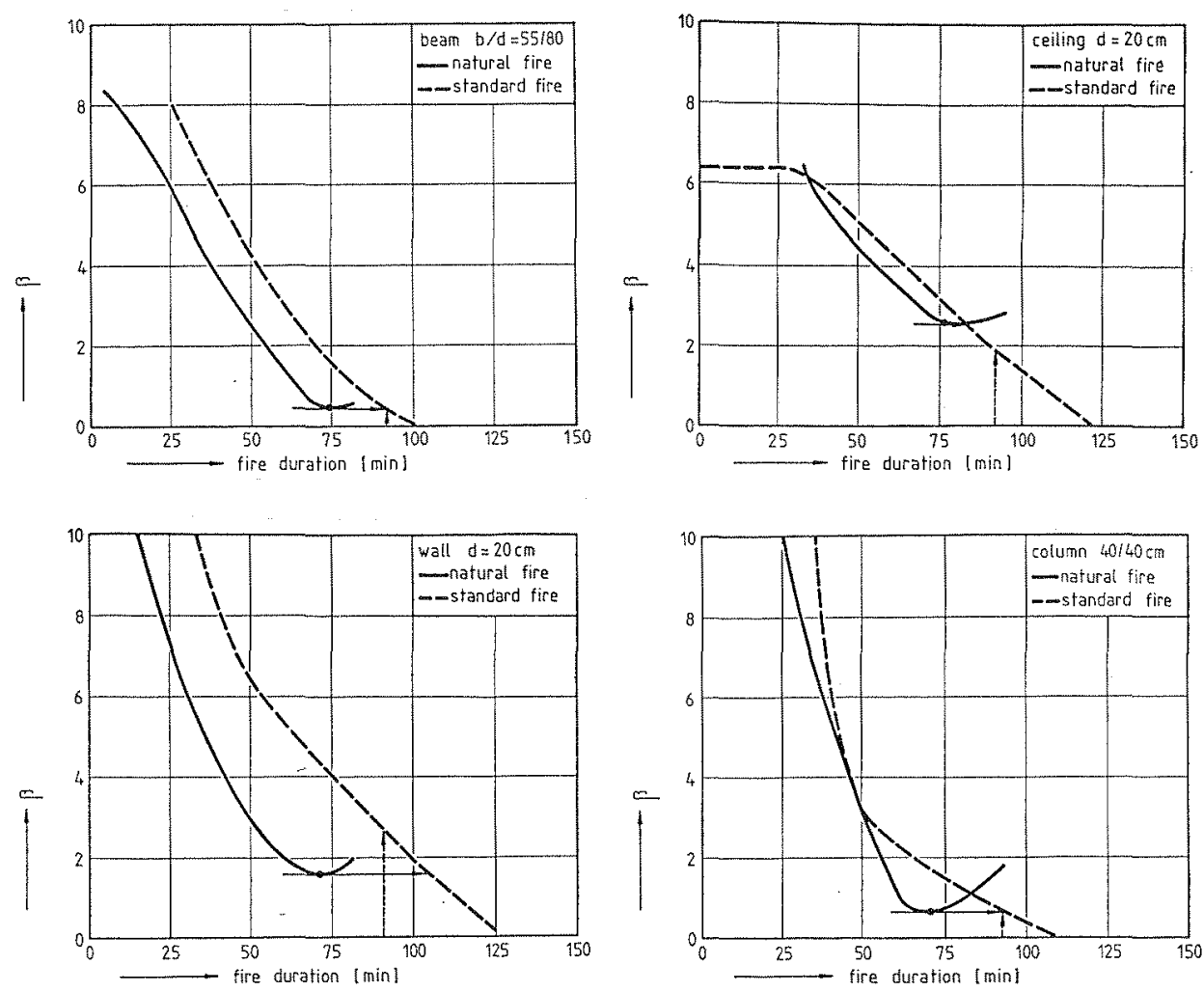

Fig. 5: Safety index $\beta$ of the investigated structural members

\subsection{Results of the Reliability Analysis}

The safety index $B$ of the investigated members are shown in Fig. 5 for standard and natural fire exposures. During standard fires the $F 90$ class elements fail in the range of 100 to 125 minutes $(B=0)$, whereby beams and column approach the lower and ceilings and walls the upper limit. 'The probabilities of failure after attaining the nominal fire duration of 90 minutes are of the order of 25 to 30 percent (beams, columns) and 0.5 to $2 \%$ (ceilings, walls). In this case the failure probabilities under natural fire conditions are of the same order as under a standard fire after 85 to 90 minutes.

The overall variations $\left(\sigma_{z}\right)$ during the natural fire are partly more than $100 \%$ larger than under standard fire conditions, due to i) the larger scattering of $\mathrm{T}_{\mathrm{b}, \mathrm{s}}$ and $\left.i \mathrm{i}\right)$ the additional influence of scattering loads. In both types of fire the variations of the member temperatures are dominating. Beside this, the yield strength of the steel, the concrete strength in connection with the analysis of columns and the live loads contribute to the overall variations; the remaining parameters are negligible. 


\subsection{Safety Elements for Fire Safety Design}

From section 4.3 safety elements for practical fire safety design of structural elements may be derived. The required safety level is described by a target safety index $B$ depending on the occurence rate of fires in a compartment, the active fire protection measures taken to prevent a fire from spreading within the whole compartment, and perhaps the total damage due to a severe fire.

Informations on the influences of parameter uncertainties are taken from the weighting factors $\alpha_{X_{i}}$ of the basic variables $X_{i}$ in Tab. 2 (cf. section 4.2 ). The values $\alpha_{x}$ for the structural elements of Fig. 3 in the most critical phase of the naturat fire as well as the respective values after the equivalent fire duration of the standard fire are summarized in Tab. 2 .

Tab. 2: Weighting factors $\alpha x$. of the basic variables $X_{i}$ for the structural elements in the natural and the standard fire

\begin{tabular}{|c|c|c|c|c|c|c|c|c|}
\hline \multirow{3}{*}{$\begin{array}{l}\text { basic } \\
\text { variable } \\
X_{i}\end{array}$} & \multicolumn{8}{|c|}{$\alpha_{X}$ for structural elements } \\
\hline & \multicolumn{2}{|c|}{ ceiling } & \multicolumn{2}{|c|}{ beam } & \multicolumn{2}{|c|}{ wall } & \multicolumn{2}{|c|}{ column } \\
\hline & $\mathrm{n}$ & s & $\mathrm{n}$ & $\mathrm{s}$ & n & $\mathrm{s}$ & $n$ & $\mathrm{~s}$ \\
\hline T & & & & & & & & \\
\hline $\mathrm{T}_{\mathrm{S}}$ & -0.990 & -0.837 & -0.971 & -0.881 & -0.971 & -0.911 & -0.853 & -0.617 \\
\hline $\begin{array}{l}T_{b} \\
B_{0}\end{array}$ & 0.001 & 0.011 & 0.003 & 0.007 & 0.0 & 0.0 & 0.511 & 0.778 \\
\hline$B_{S}^{K}$ & 0.126 & 0.244 & 0.076 & 0.151 & 0.040 & 0.098 & 0.004 & 0.01 \\
\hline $\mathrm{E}_{\mathrm{b}}^{\mathrm{S}}$ & 0.0 & 0.0 & 0.0 & 0.0 & 0.0 & 0.0 & 0.001 & 0.001 \\
\hline $\mathrm{E}_{\mathrm{S}}^{\mathrm{b}}$ & 0.0 & 0.0 & 0.0 & 0.0 & 0.0 & 0.0 & 0.001 & 0.001 \\
\hline $\mathrm{h}_{\mathrm{S}}^{\mathrm{s}}$ & 0.023 & -0.142 & 0.028 & 0.041 & 0.235 & 0.400 & 0.080 & 0.116 \\
\hline $\mathrm{g}^{\mathrm{S}}, \mathrm{N}_{\mathrm{g}}$ & -0.012 & -0.100 & -0.053 & -0.098 & 0.001 & 0.013 & -0.017 & -0.026 \\
\hline $\mathrm{P}, \mathrm{N}_{\mathrm{p}}^{\mathrm{s}}$ & -0.054 & -0.458 & -0.218 & -0.436 & 0.002 & 0.012 & -0.066 & -0.025 \\
\hline
\end{tabular}

$\mathrm{n}=$ natural fire

$\$=$ standard fire

It is proposed to define design values of the basic variables with the target safety index $B$ and the following conservative weighting factors:

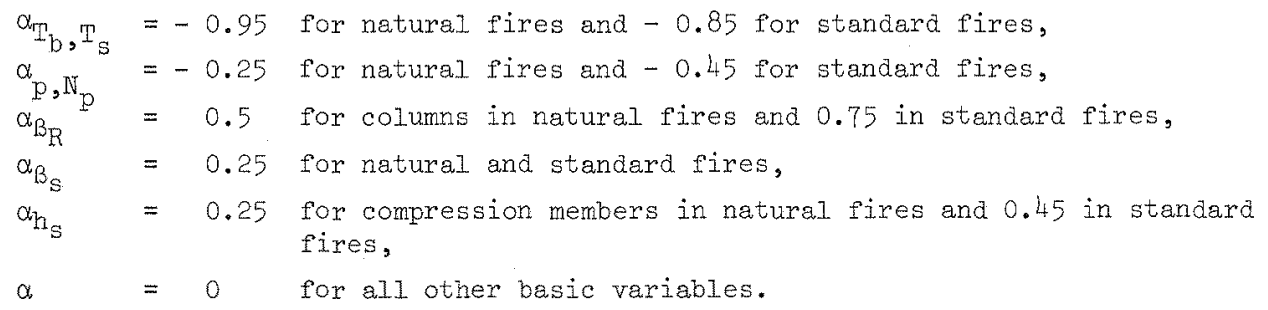

These design values may also be expressed with the help of the nominal values given in Tab. 1 and partial safety factors $\gamma$ as indicated in Tab. 3 for a range of the safety index $2.0 \leqq \beta \leqq 3.5$ (valid for nuclear power plant compartments). In practical applications the partial safety factors for $B_{R}, B_{s}$ and $h_{s}$ should be taken as $\sim 1.0$. 
Tab. 3: Partial safety factors $y$ for the most important basic variables and design for natural and standard fires

\begin{tabular}{|c|c|c|c|c|c|c|c|c|c|}
\hline \multirow{3}{*}{$\begin{array}{l}\text { basic } \\
\text { variable }\end{array}$} & \multirow[t]{3}{*}{ B } & \multicolumn{8}{|c|}{$\gamma$ for structural element } \\
\hline & & \multicolumn{2}{|c|}{ ceiling } & \multicolumn{2}{|c|}{ beam } & \multicolumn{2}{|c|}{ wall } & \multicolumn{2}{|c|}{ column } \\
\hline & & $n$ & $s$ & $\mathrm{n}$ & $s$ & $n$ & $S$ & n & 5 \\
\hline$T, T_{b}, T_{S}$ & $\begin{array}{l}2.0 \\
3.5\end{array}$ & $\begin{array}{l}1.43 \\
1.97\end{array}$ & $\begin{array}{l}1.18 \\
1.34\end{array}$ & $\begin{array}{l}1.43 \\
1.97\end{array}$ & $\begin{array}{l}1.18 \\
1.34\end{array}$ & $\begin{array}{l}1.43 \\
1.97\end{array}$ & $\begin{array}{l}1.18 \\
1.34\end{array}$ & $\begin{array}{l}1.43 \\
1.97\end{array}$ & $\begin{array}{l}1.18 \\
1.34\end{array}$ \\
\hline$p, \mathbb{N}_{p}$ & $\begin{array}{l}2.0 \\
3.5\end{array}$ & $\begin{array}{l}0 . \overline{46} \\
0.68\end{array}$ & $\begin{array}{l}0.63 \\
0.83\end{array}$ & $\begin{array}{l}0.46 \\
0.68\end{array}$ & $\begin{array}{l}0.63 \\
0.83\end{array}$ & $\begin{array}{l}0.46 \\
0.46\end{array}$ & $\begin{array}{l}0.46 \\
0.46\end{array}$ & $\begin{array}{l}0.46 \\
0.46\end{array}$ & $\begin{array}{l}0.46 \\
0.46\end{array}$ \\
\hline${ }^{B} \mathrm{R}$ & $\begin{array}{l}2.0 \\
3.5\end{array}$ & $\begin{array}{l}0.79 \\
0.79\end{array}$ & $\begin{array}{l}0.79 \\
0.79\end{array}$ & $\begin{array}{l}0.79 \\
0.79 \\
\end{array}$ & $\begin{array}{l}0.79 \\
0.79 \\
\end{array}$ & $\begin{array}{l}0.79 \\
0.79\end{array}$ & $\begin{array}{l}0.79 \\
0.79\end{array}$ & $\begin{array}{l}0.91 \\
1.02\end{array}$ & $\begin{array}{l}0.98 \\
1.16 \\
\end{array}$ \\
\hline$B_{s}$ & $\begin{array}{l}2.0 \\
3.5\end{array}$ & $\begin{array}{l}0.93 \\
0.96\end{array}$ & $\begin{array}{l}0.93 \\
0.96\end{array}$ & $\begin{array}{l}0.93 \\
0.96\end{array}$ & $\begin{array}{l}0.93 \\
0.96\end{array}$ & $\begin{array}{l}0.93 \\
0.96\end{array}$ & $\begin{array}{l}0.93 \\
0.96\end{array}$ & $\begin{array}{l}0.93 \\
0.96\end{array}$ & $\begin{array}{l}0.93 \\
0.96\end{array}$ \\
\hline $\mathrm{h}_{\mathrm{s}}$ & $\begin{array}{l}2.0 \\
3.5\end{array}$ & $\begin{array}{l}1.0 \\
1.0\end{array}$ & $\begin{array}{l}1.0 \\
1.0\end{array}$ & $\begin{array}{l}1.0 \\
1.0\end{array}$ & $\begin{array}{l}1.0 \\
1.0\end{array}$ & $\begin{array}{l}0.88 \\
0.78\end{array}$ & $\begin{array}{l}0.78 \\
0.61\end{array}$ & $\begin{array}{l}0.88 \\
0.78\end{array}$ & $\begin{array}{l}0.78 \\
0.61\end{array}$ \\
\hline
\end{tabular}

$\mathrm{n}$ = natural fire

$s=$ standard fire

\section{CONCLUSION}

The report describes the theoretical determination of failure probabilities for structural members in NPP. Models for the determination of fire effects are presented. The temperature-time curves are evaluated by post-flashover heat models, whereby the effect of forced ventilation in the safety related buildings of the power plants is accounted for. Based on the reliability analyses also safety elements for practical fire safety design of structural elements are derived depending on a target reliability. It seems sufficient to define partial safety factors for the member temperatures and reduction factors for the nominal live loads whilst all other parameters may be used with their nominal values.

\section{REFERENCES}

11/ DIN 4102: Brandverhalten von Baustoffen und Bauteilen, Beuth-Verlag, Berlin, Sept. 1977 .

12/ ABK/GRS: Optimization of fire protection measures and guality control in nuclear power plants. Final report of the research project SR $144 / 1$ sponsored by the Federal Minister of the Interior. Draft December 1984 (in German).

13/ DIN 1045: Beton und Stahlbeton, Bemessung und Ausführung, Beuth-Verlag, Berlin, Dez. 1978.

14/ CEB (Comité Euro-Intemational du Béton): Design of Concrete Structures for Fire Resistance, Bulletin d'Information No. 145, Paris, Ja. 1982.

/5/ Hosser, D. und U. Schneider: Sicherheitsanforderungen für brandschutztechnische Nachweise von Stahlbetonbauteilen nach der Wärmebilanztheorie, VfdB-Zeitschrift, Heft $1 / 82$ und $2 / 82,1982$.

16/ König,D.: D. Hosser; W. Schobbe: Sicherheitsanforderungen für die Bemessung von baulichen Anlagen nach deñ Empfehlungen des NABau, Bauingenieur $\mathrm{Nr} .57, \mathrm{~S} .69 / 78,1982$.

/7/ Hosser, D. und U. Schneider: Sicherheitskonzept für brendschutztechnische Nachweise nach der Wärmebilanztheorie, Forschungsbericht If'Bt, Berlin, Dez. 1980.

18/ KNA 2101.1: Branaschutz in Kernkraftwerken, Tei1 1: Grundsätze des BrandSchutzes, Regelentwurf, Köln, Juni 1984. 